\title{
Reduction of vibration in railway surfaces
}

\author{
Krzysztof Koziol ${ }^{1, *}$ \\ ${ }^{1}$ Cracow University of Technology, Institute of Structural Mechanics, 31-155 Kraków, Warszawska \\ 24 St., Poland
}

\begin{abstract}
Presented paper concerns the problem of reduction of the impact of vibrations generated by the metro on neighboring buildings and people staying inside. The issue of acceptable levels of these impacts in accordance with Polish standards and ISO (International Standard Organization) has been discussed. Basing on the example of research carried out by the author in the Warsaw Metro and his experience acquired during the design of vibroisolations of the final section of the first subway line in Warsaw, methods of testing dynamic interactions and predicting their level using FEM and simulation calculations on models were presented
\end{abstract}

\section{Impact of metro traffic on buildings and people in buildings}

Main impact of the subway on the environment is related with emission of vibrations generated by the passage of trains in the tunnel. These vibrations spread in the soil (as a result of wave propagation) and affect neighboring buildings and people in these buildings (Fig. 1).

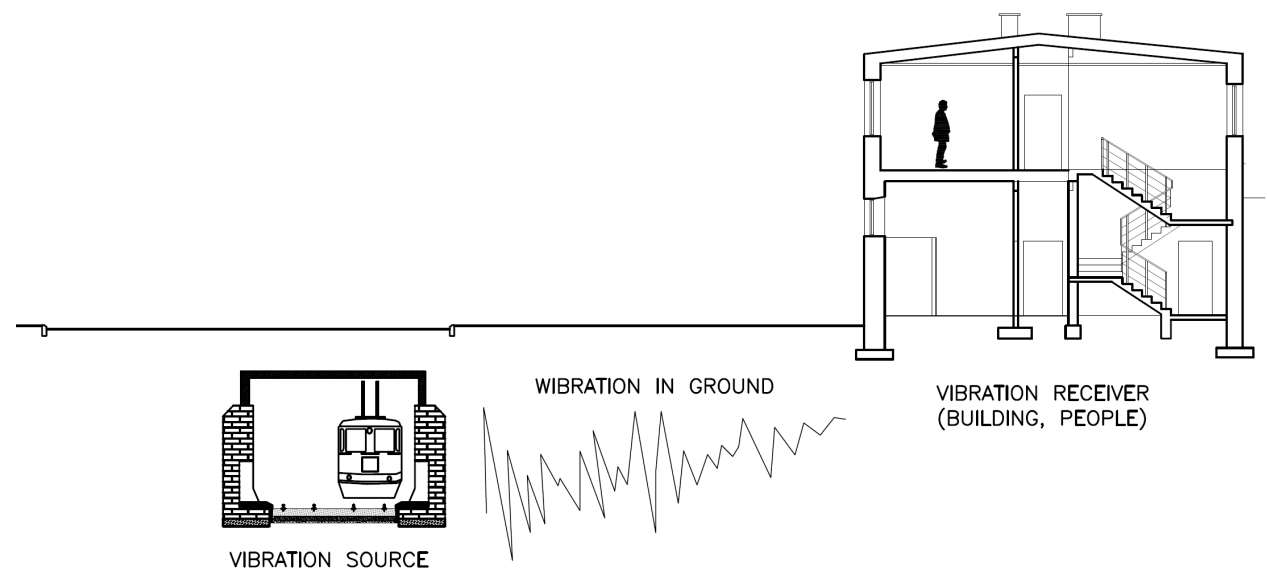

Fig. 1. Diagram of vibration emission from the subway tunnel.

* Corresponding author: kkoziol@pk.edu.pl 
The best way to avoid mentioned nuisance associated with these influences is to reduce the vibrations emitted from the subway tunnel by choosing the appropriate structure of the rail surface with usage of vibroinsulating elements. Well-designed vibration isolation of the rail surface gives a significant reduction of the level of vibrations emitted to the environment. Below are presented scientific-research issues regarding the proper selection of the rail surface structure due to limitation of mentioned vibration emission so that the permissible vibration levels specified in the relevant standards are not exceeded [1-4].

\section{Acceptable levels of interactions according to Polish and ISO standards requirements}

The legal basis and detailed regulations related to assessments of the impact of vibrations on buildings and people in buildings are contained in two Polish standards PN-B02170:2016 - Assessment of harmfulness of vibration transmitted by the ground on buildings [3] and PN-B-02171:2017 - Assessment of the impact of vibrations on people in buildings [4].

Vibrations measured at appropriate points of the structure or obtained as a result of numeric calculations based on input data from such measurements are assessed. Generally measurements concern three components of vibrations: two mutually perpendicular horizontal directions marked " $\mathrm{x}$ " and " $\mathrm{y}$ " and a vertical component " $\mathrm{z}$ ".

The PN-B-02170:2016 standard provides two ways of assessing the impact of vibrations onto building structure:

- full assessment - applicable for each type of building,

- approximate assessment (using scales of dynamic impact SWD-I and SWD-II) applicable only two specific building classes.

Full assessment of the impact of vibrations on the building structure should be made in accordance with principles of building dynamics calculations. This requires preparing a FEM model of the building that could be used for dynamic calculations (Figure 2) and forcing its vibrations. This could be done either by applying vibrations to the foundations measured or predicted.

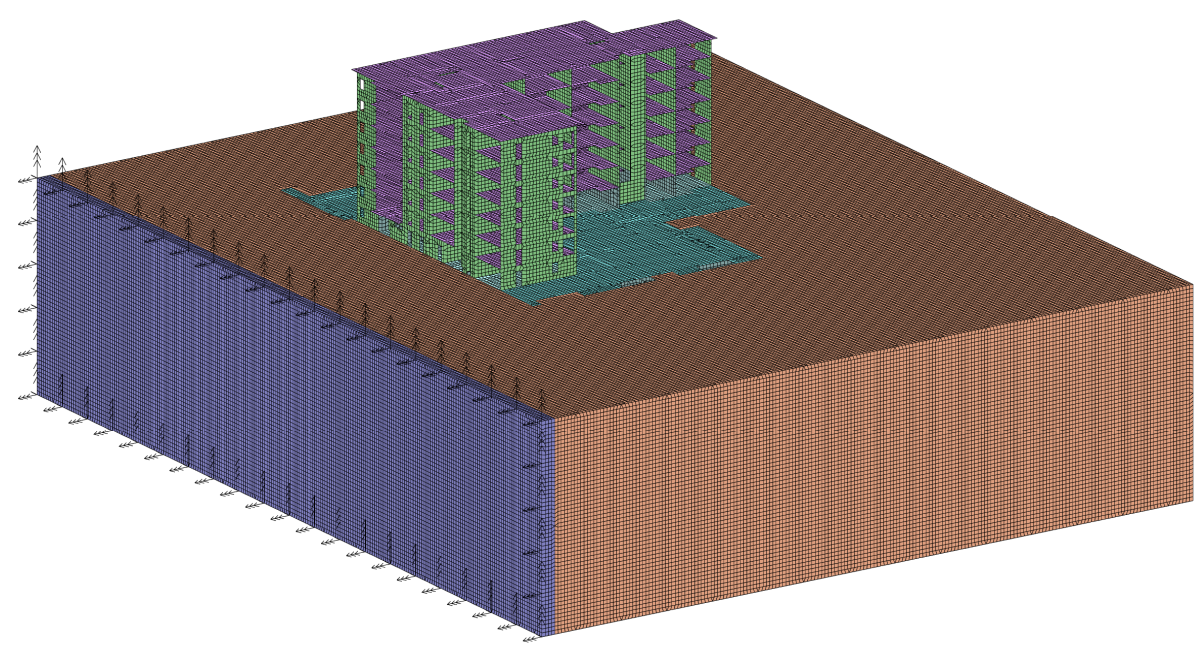

Fig. 2. Visualization of the MES model. 
Mentioned assessment consists in determination of inertia forces acting additionally on the structure during vibrations, loading of the FEM model with all static and dynamic loads and checking the strength of such loaded structure in accordance with requirements of existing standards for static calculations and structure design

Taking into account labor consumption of the calculations discussed above and the fact that horizontal vibrations have a decisive influence onto structure of buildings, the approximate way of assessing dynamic influences (precisely influence of horizontal vibration components) on the building using of so-called dynamic influence scale: SWD-I and SWDII were introduced. These scales concern buildings made of masonry elements (intended for manual laying such as bricks, hollow bricks, etc.) and prefabricated using large-blocks and large-panels.

The SWD-I scale [4] refers to buildings with a compact shape, small external dimensions of a plan projection (not exceeding $15 \mathrm{~m}$ ), one or two-story and with a height not exceeding any of the plan projection dimensions.

The SWD-II scale [4] refers to buildings no higher than five floors, which height is smaller than the double smallest building width in a plan projection and to low buildings (up to two floors) but not fulfilling conditions specified for the SWD-I scale.

Evaluation consists of horizontal components of the building vibrations, measured in a rigid node of the structure (from the source of vibrations) in the ground level or on the foundation of the building. Recorded vibrations are analyzed in order to determine the maximum peak values of displacements or accelerations amplitudes (vertical axis of the scale) in individual frequency bands (horizontal axis of the scale). Based on the results of the analyzes, buildings vibrations could be qualified o one of five harmful zones:

- $\quad$ zone I - vibrations imperceptible for the building;

- $\quad$ zone II - vibrations perceptible by the building, but not harmful to its construction;

- $\quad$ zone III - vibrations harmful to the building, causing local scratches and cracks;

- zone IV - vibrations of high harmfulness to the building, posing a threat to human safety;

- zone V - vibrations causing building failure due to wall collapse, falling ceilings, etc. The building cannot be used.

Fig. 3 presents exemplary results of chosen building vibration analysis in 1/3 octave bands in the case of the assessment of the impact of these vibrations using SWD-I and SWD-II scales - vibrations are imperceptible for the building.

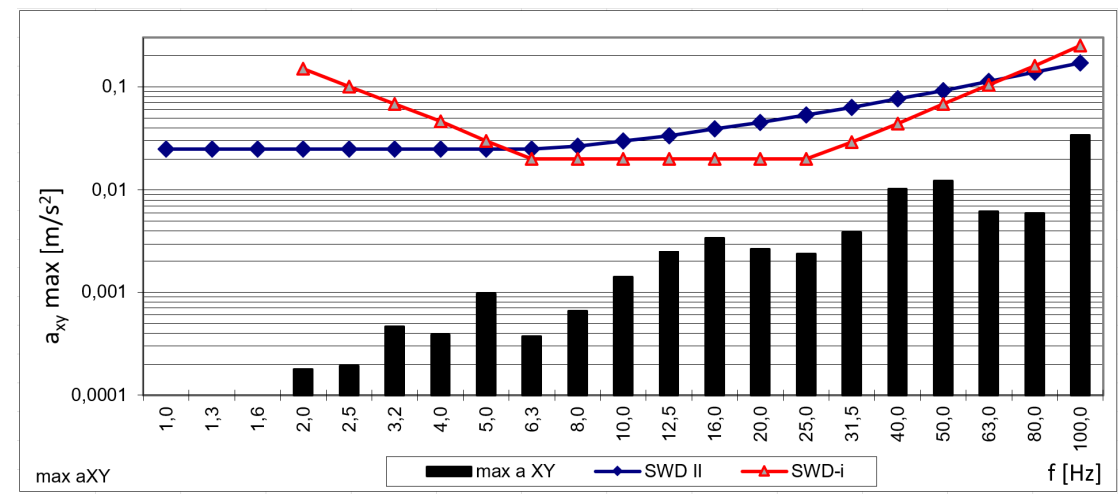

Fig. 3. An exemplary assessment of the impact of vibrations on a building using the SWD-II scale.

Evaluation of the impact of vibrations on people is performed in Poland on the basis of PN/B-02171:2017 and international standards : ISO 2631-2 [1] and ISO 10137 [2].. This 
standard defines the thresholds of perceived vibrations by people and allowable values of mechanical vibration parameters to ensure the required comfort of people staying inside building, depending on:

- purpose of the room inside the building (residential, offices, workshops, hospitals, precise laboratories, etc.);

- time of the day when vibrations occur (day i.e. from 6 am to $2 \mathrm{pm}$ or night, i.e. from 8 pm to $6 \mathrm{pm})$;

- nature and repeatability of vibrations;

- direction of vibrations (horizontal or vertical) and position of human during reception of vibrations (standing or lying).

These values concern vibrations in the vertical direction " $z$ " (along the axis of human spine) and vibrations in the "xy" directions (horizontal vibrations, transverse directions to the axis of the spine). Described assessment is based on the results of frequency analysis of vibrations recorded at the place of their reception by human. As a result of such analysis effective values of accelerations (or velocities) vibrations so-called RMS (root mean square) in $1 / 3$ octave (terce) frequency bands are obtained and compared with the permissible values of these parameters. Permissible values are determined by multiplying the vibration perceptibility threshold value by the multiplier $\mathrm{n}$ given in table 1 .

Table 1. Values of the " $n$ " coefficient according to PN-B-02171:2017 [4]

\begin{tabular}{|c|c|c|c|}
\hline \multirow[b]{2}{*}{ Purpose of the room } & \multirow[b]{2}{*}{$\begin{array}{l}\text { Time of the } \\
\text { day }\end{array}$} & \multicolumn{2}{|c|}{ Value of the coefficient during vibrations: } \\
\hline & & $\begin{array}{c}\text { Fixed (continuous or intermittent) } \\
\text { with a multiplicity greater than } 10 \\
\text { per day }\end{array}$ & Occasional \\
\hline \multirow{2}{*}{$\begin{array}{c}\text { Hospitals (operating rooms), } \\
\text { precise laboratories }\end{array}$} & Day & \multirow{2}{*}{1} & \multirow{2}{*}{1} \\
\hline & Night & & \\
\hline \multirow{2}{*}{ Hospitals (patients rooms) } & Day & 2 & 8 \\
\hline & Night & 1 & 4 \\
\hline \multirow{2}{*}{ Apartments } & Day & 4 & 32 \\
\hline & Night & 1,4 & 4 \\
\hline \multirow{2}{*}{ Offices. schools } & Day & \multirow{2}{*}{4} & \multirow{2}{*}{64} \\
\hline & Night & & \\
\hline \multirow{2}{*}{ Workshops } & Day & \multirow{2}{*}{8} & \multirow{2}{*}{128} \\
\hline & Night & & \\
\hline
\end{tabular}

The comfort limits as a function of vibration acceleration are shown in Fig. 4.

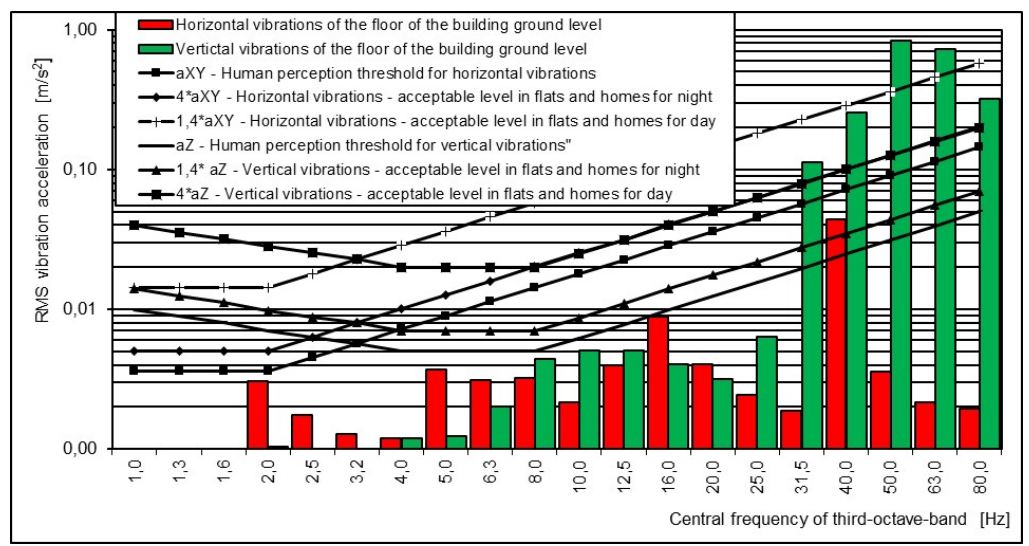

Fig. 4. Impact of vibrations on people in homes. 
Analysis results of the impact of vibrations on humans can be briefly expressed using the WODL(f) index - human perception of vibrations index. This ratio expresses the highest value of the ratio of the effective value of acceleration (or velocity) determined due to analysis of vibrations (obtained from measurement or calculation) - RMSa(f) to the effective acceleration (or velocity) value corresponding to the human vibration perceptibility threshold in the same $1 / 3$ octave (terce) frequency band. The value of the WODL index is given together with the information about the central frequency of the $1 / 3$ octave band in which WODL is determined $-\min ((a X Y(f), a Z(f))$

$$
\text { WODL }(f)=\max (\operatorname{RMSa}(f) / \min ((a X Y(f), a Z(f))
$$

Many times during analysis of impact of vibrations on people, frequency is omitted giving only the maximum value of the WODL coefficient. As a result one loses information about the frequency at which the threshold of perceived vibrations is exceeded.

In an analogous manner, in buildings where the impact of vibrations is assessed using the SWD scales, one can determine the building vibration perception index - WODB. It is defined as the maximum value of the ratio of the peak value of acceleration (or displacement) to the acceleration (or displacement) value corresponding to the vibration perceptibility limit of the building in the same 1/3 octave (terce) frequency band (specifying the center frequency of this band).

\section{Methodology of investigating dynamic interactions and forecasting their level on the example of research conducted in the Warsaw Metro}

Based on the author's many years of experience related to studies of vibrations induced by metro operation as well as analysis of the impact of these vibrations on neighboring buildings and people inside buildings [5] a scheme was developed to account for these impacts in the case of the construction of rail structure on new subway sections (Fig. 5). This scheme can also be used in the case of modernization of the track structure (metro, tram, etc.).

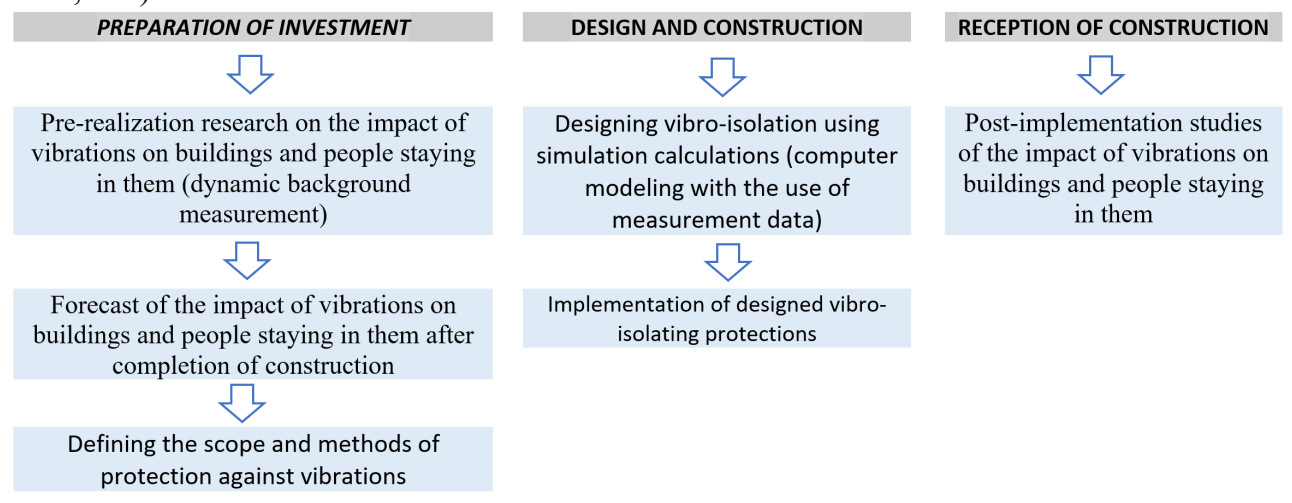

Fig. 5. The scheme of taking into account environmental impact of vibrations in case of construction of a subway rail.

Procedures described above have been successfully used for a long time during the construction of subsequent metro sections in Warsaw. As an example, it is possible to 
provide activities undertaken on the final section of the first metro line in Warsaw, comprising three stations and three track tunnels (approx. $3 \mathrm{~km}$ ). Within the dynamic impacts of the subway zone, whose range was in Warsaw (shallow subway) was set at $40 \mathrm{~m}$ in a plane projection from the outer walls of the tunnel, there were 129 buildings, of which 36 were selected as a representative structures in order to perform dynamic background measurements and vibration impact predictions. Earlier in all buildings, an inventory of the technical condition of their structure was carried out (along with photographic documentation of damages), and then in representative buildings the following activities were taken: dynamic background measurements and prediction of impact of vibrations onto building and people staying in the building. Because in a significant number of buildings the predicted level of vibration impact on people was too high (significant exceeding of the human vibration threshold) it was necessary to design in the track tunnel (fig. 6) at segments where these buildings are located, the new non ballasted track using the EBS system (Embedded Block System) produced by Edilon and, where it was necessary, also anti-vibration mats (fig. 7).

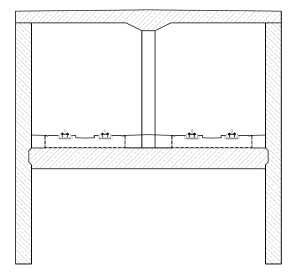

Fig. 6. Schematic cross section of the Warsaw metro tunnel within the final section of the first Warsaw metro line.

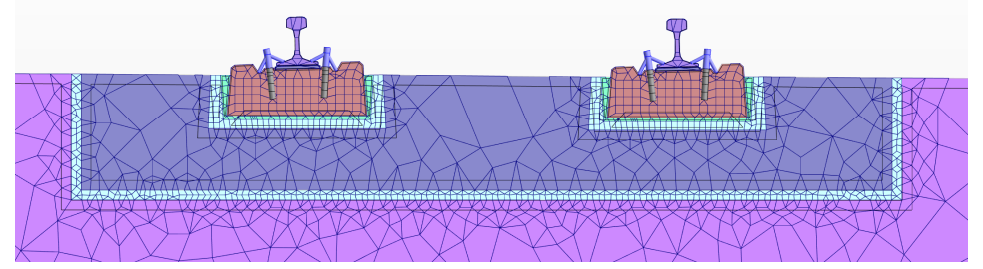

Fig. 7. Diagram of the subway rail details with EBS Edilon and vibration isolation mat.

Computational models (FEM) for both analysed cases were constructed; material parameters of individual elements were determined based on laboratory test or assumed as suggested in standards, remembering (especially for soil elements) about their possible deviations. Presented results include values obtained for boundary and mean values (in the sense of the arithmetic average) of material parameters. In case of models extended with an additional vibration insulation layer, a mat with a thickness of 2 and $2.5 \mathrm{~cm}$ and with a dynamic stiffness (depending on frequency and pressure) ranging from 0.014 to $0.02 \mathrm{~N} /$ $\mathrm{mm} 3$ was used. In the presented analysis it was assumed that the damping of the mat expressed by the loss angle $\operatorname{tg}(\tau)$ is equal to 0.3 . Onto the vibration propagation path, there are places where a special approach requiring experimental verification should be applied. These include the point of contact between two different mediums. In this case, it is required to perform experimental tests that will verify the parameters applied at the interface contact. An exemplary function of the transition between the ground and the building is described in [6-8] and in Figure 8. As can be seen from Fig. 10, the amplitudes characterising lower frequencies (both horizontal and vertical) can increase during transition from the ground to the building. 


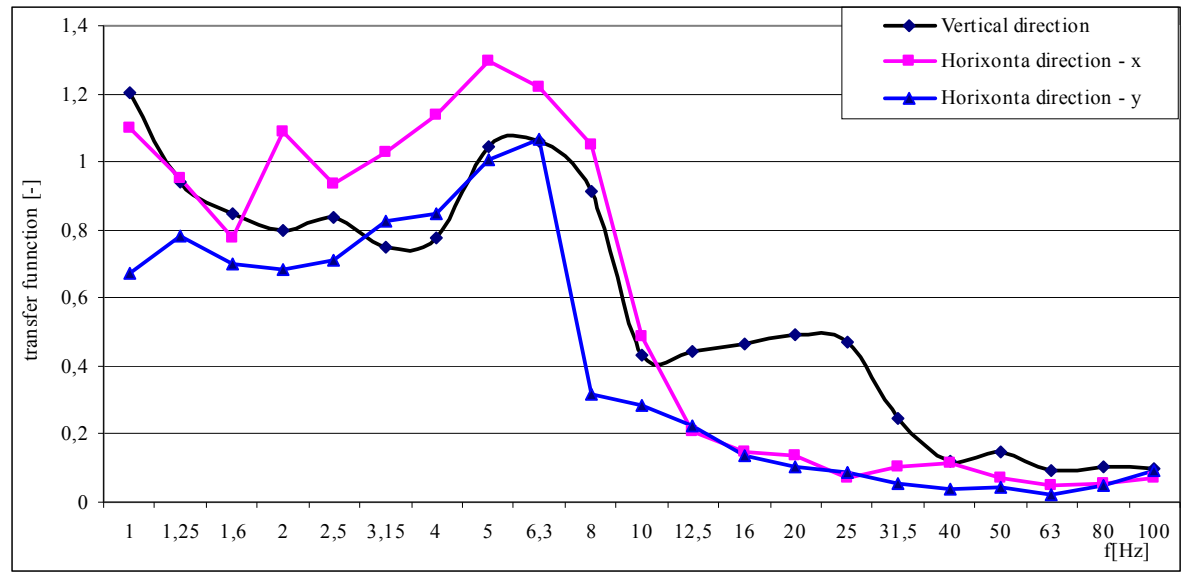

Fig 8. Transfer function of the acceleration from the ground to building for the vertical direction $\mathrm{z}$ and horizontal directions $\mathrm{x}, \mathrm{y}[8]$.

At the beginning sense of usage of such a rail structure was analyzed. For this purpose, analyzes of the human perception of vibrations index (WODL) were made in one of investigated building namely most exposed to vibrations, assuming different variants of vibration isolation or lack thereof. An exemplary analysis is presented in Fig. 6. Selected results of these analyzes are presented in Table 2, showing the most unfavorable values of the human perception of vibrations index (WODL) obtained from described analyzes.

Table 2. List of the most unfavorable results of simulation calculations of the impact of vibrations on people in the K61 building at different variants of the track structure.

\begin{tabular}{|c|c|c|}
\hline Construction variant & WODL index & Comments \\
\hline $\begin{array}{c}\text { Existing typical construction of the metro rail structure in the route } \\
\text { tunnel without any vibro-isolation }\end{array}$ & 13,9 & Inadeąuate protection \\
\hline $\begin{array}{c}\text { Structure of the rail track in the route tunnel with EBS, bottom } \\
\text { plate } \mathbf{6 0} \mathbf{~ c m} \text { thick, without vibro-insulating mat }\end{array}$ & 4,7 & Inadeąuate protection \\
\hline $\begin{array}{c}\text { Structure of the rail track in the route tunnel with EBS, bottom } \\
\text { plate } \mathbf{6 0} \mathbf{~ c m} \text { thick, with } \mathbf{2 . 0} \text { cm thick mat }\end{array}$ & 1,7 & Inadeąuate protection \\
\hline $\begin{array}{c}\text { Structure of the rail track in the route tunnel with EBS, bottom } \\
\text { plate thickened up to } \mathbf{7 0} \mathbf{~ c m} \text {, with } \mathbf{2 . 0} \mathbf{~ c m} \text { thick mat }\end{array}$ & 1,1 & Inadeąuate protection \\
\hline $\begin{array}{c}\text { Structure of the rail track in the route tunnel with EBS, bottom } \\
\text { plate thickened up to } \mathbf{8 0} \mathbf{~ c m} \text {, with } \mathbf{2 . 5} \mathbf{~ c m} \text { thick mat }\end{array}$ & $\mathbf{0 , 7}$ & Adequate protection \\
\hline
\end{tabular}

Conducted analysis shows that usage of the EBS system alone in the analyzed building reduces the WODL index by as much as $66 \%$. Despite such a significant reduction $\mathrm{f}$ the impact of vibrations on people, only the combined use of EBS and vibroinsulating mat (with thickening the bottom plate up to $80 \mathrm{~cm}$ ) reduced the value of this index to the required level (below 1.0).

\section{Summary}

Impact of vibrations on neighboring buildings and particularly on the residents of these buildings is currently the main problem in the field of environmental protection in the case of subway operation. Primary method of reducing the level of vibration generated by subway is usage of isolation in the rail surface. Usage of an appropriate vibroisolation 
solution in the construction of a rail surface should be result of designing process of vibroisolation using simulation calculations. The necessity to make calculations confirming the achievement of the required effectiveness of vibroisolation (lowering the level of impact of vibrations on people below the level of perceptibility of these vibrations) in the case of its specific application results from the dependence of vibroisolation effects on many factors e.g.: damping properties of vibroinsulating material, dimensions of used elements, e.g. thickness of vibroisolation mats (taking into account surface deformation), rail stiffness, spacing of supports (supports or block supports) and resulting rail deflections and consequently, changes in excitation characteristics, structure and dimensions (mass) of sub-floor slabs, foundation rigidity, tunnel casing construction, ground and water conditions during propagation from tunnel to building, structure and dynamic features of the building receiving vibrations. As described in the above article in the case of appropriately designed two-stage vibration isolation consisting of the EBS system in combination with usage welldesigned (good in terms of dynamic features) vibration isolating mat one can achieve high efficiency, reducing the impact on people in buildings below the threshold of perceptibility vibration by humans.

\section{References}

1. ISO 2631-2; Guide to the evaluation of human exposure to whole body vibration. Part 2 - Vibration in buildings, (2003)

2. ISO 10137, Bases for design of structures - Serviceability of buildings and walkways against vibrations, (2007)

3. PN-B-02170:2016 Evaluation of the harmfulness of building vibrations due to ground motion (in Polish)

4. PN-B-02171:2017 Evaluation of vibration influence on people in buildings (in Polish).

5. Kozioł K. Influence of different structural solutions for dynamic response of the modernized building. IOP Conference Series: Materials Science and Engineering -, Vol. 245,dings (in Polish) (2017)

6. Kozioł K. Influence of excitations originating from moving subway onto transferring vibrations from ground to structure. E3S Web of Conferences [online]. - 2016, Vol. 10, 1st International Conference on the Sustainable Energy and Environment Development SEED 2016, Krakow, Poland, (2016)

7. Kozioł $\mathrm{K}$ The influence of vibration propagation from trams on building vibration caused by ground shaking. Proceedings of the Fifteenth International Conference on Civil, Structural and Environmental Engineering Computing, [Prague - Czech Republic, 1-4 September 2015] [USB] / ed. by J. Kruis, Y. Tsompanakis, B. H. V. Topping. - Stirlingshire, UK : Civil-Comp Press, (2015)

8. Kozioł K., „A comparison of the vibration effects caused by city transportation systems on the occupants of buildings", CCMM Prague-Czech Republic, (Sept. 2015) 